\title{
Psychosocial and psychiatric risk factors for suicide
}

\author{
Case-control psychological autopsy study* \\ ANDREW T. A. CHENG, TONY H. H. CHEN, CHWEN-CHEN CHEN \\ and RACHEL JENKINS
}

\section{Background Few studies of suicide have simultaneously examined the individual and combined effects of psychosocial and psychiatric risk factors.}

\begin{abstract}
Aims To do so in a representative sample of suicides.
\end{abstract}

\begin{abstract}
Method Acase-control psychological autopsy was conducted among 113 consecutive suicides and 226 living controls matched for age, gender, ethnicity and area of residence in Taiwan.
\end{abstract}

\section{Results Five major risk factors (loss event, suicidal behaviour in first-degree relatives, ICD-10 major depressive episode, emotionally unstable personality disorder and substance dependence) were found to have independent effects on suicide from multivariate conditional logistic regression analysis.}

\section{Conclusions Effective intervention} and management for loss event and major depressive episode among emotionally unstable subjects with a family tendency of suicidal behaviour, frequently also comorbid with alcohol or other substance dependence, may prove to be most effective for suicide prevention in different populations.

Declaration of interest The work was supported by a grant from the National Science Council, Taiwan (NSC79-030I-H002-04/NSC80-030IH002-07).

*Presented in part at the XIXCongress of the International Association for Suicide Prevention, Adelaide, 17 April 1997, and the XVI Congress of the World Association for Social Psychiatry, Vancouver, BC, 20 August 1998.
Psychological autopsy studies among suicides have consistently found a high prevalence of mental disorders in people who have committed suicide in both Eastern (Cheng, 1995; Cheng et al, 1997) and Western countries (e.g. Robins et al, 1959; Barraclough et al, 1974; Lesage et al, 1994; Shaffer et al, 1996; Foster et al, 1999). The most common types of disorder have been depressive illness and alcoholism.

A number of psychosocial risk factors have also been reported to be significantly associated with the risk of suicide. They include marital disruption, unemployment, lower socio-economic status, living alone, a recent migration, early parental deprivation, family history of suicidal behaviour and psychopathology, poor physical health and stressful life events (Sainsbury, 1986; Heikkinen et al, 1994; Gould et al, 1996; Foster et al, 1999).

Few of those studies, however, simultaneously examined the individual and combined effects of psychosocial and psychiatric factors on the risk of suicide. One recent study that has done this was conducted among 120 young suicides and 147 matched community controls in the New York City metropolitan area and the entire state of New Jersey, USA (Gould $e t$ al, 1996). The investigators found comparable effects of psychosocial factors and psychopathology on the risk of suicide. There was no significant interaction between the two sets of risk factors. Another study (Foster et al, 1999) conducted among 117 suicides and matched living controls (1:1) in Northern Ireland also found an independent effect of life events, following adjustment for DSM-III-R Axis I disorder (American Psychiatric Association, 1987).

In our previous reports of a psychological autopsy study of suicide in Taiwan, we described the psychiatric antecedents among suicides, and their major contributions to the incremental risk for suicide (Cheng, 1995; Cheng et al, 1997). The present study aims to examine, in an Eastern country, all the important psychosocial factors preceding suicide previously reported in Western societies and their interaction with psychiatric illness.

\section{METHOD}

The subjects and methodology of this suicide study have been described in detail elsewhere (Cheng, 1995; Cheng et al, 1997) and will be briefly summarised here. Measurement of psychosocial variables that are unique to this paper will be described in detail.

\section{The sample and ascertainment of suicide}

The sample of study subjects comprised all 117 consecutive suicides ( 72 men and 45 women) identified during two and a half years from Han Chinese and two aboriginal groups (the Atayal and Ami) in East Taiwan. On the basis of prosecutors' and coroners' reports, all unnatural nonhomicidal deaths that occurred during the study period were first screened and reclassified into 'potentially suicidal', 'undetermined', and 'accidental' groups. Then all potential suicides and undetermined deaths were examined through fieldwork. Finally, the results of the fieldwork were jointly discussed by the three interviewers to decide which cases were suicides. Any case lacking a full consensus between the interviewers was classified as 'undetermined' $(n=1)$.

Of all suicides, 113 were matched with two living controls for age, gender, ethnicity and area of residence during the year before death. Controls were randomly selected from the census records for the relevant areas of residence (10 subjects were selected using a table of random numbers, then the first two who matched the index suicide for age ( \pm 5 years), gender and ethnicity were chosen).

\section{Selection of key informants and fieldwork}

Psychological autopsy interviews were conducted with key informants of suicides and their controls by a psychiatrist (A.T.A.C.) and two psychologists during a home visit about 1 month after the death occurred. Information regarding the family tree and key persons familiar with the suicides and controls were first obtained 
to find as many potential interviewees as possible. The mean number of informants interviewed was six for suicides and five for controls. In over $90 \%$ of suicides and controls, we interviewed family members who had lived with the subjects before the suicide or the interview. We were able to interview at least one key informant for each of the suicides and controls.

\section{Psychological autopsy interview}

The psychological autopsy interview was designed to assess prior mental disorder, personality disorder, physical disorder, family history, stressful life events and socio-demographic data.

\section{Assessment of prior mental and personality disorder}

The study used a semi-structured interview, modified from that used by Barraclough $e t$ al (1974), to fulfil the requirements for current international diagnostic systems for mental disorders. The ICD-10 (World Health Organization, 1992) version of the Standardized Assessment of Personality (Mann et al, 1981), translated into Chinese, was applied to assess personality disorders. Additional medical information about previous physical and mental health, and any suicide notes, were collected from the family, medical practitioners and coroners.

Reliability and psychiatric diagnosis. The interrater reliability over the interview items between the three interviewers was examined in a pre-test $(\kappa$ coefficients ranged from 0.78 to 1.0 ). A.T.A.C., who was not blind to subjects' case/control status, made psychiatric diagnoses of suicides and controls according to DSMIII-R and ICD-10. However, two post boc reliability studies were conducted for personality disorder and other mental disorders between A.T.A.C. and one Taiwanese and one British senior psychiatrist, who made independent diagnoses based on clinical data of several suicides $(n=29)$, accidental deaths $(n=7)$ and controls $(n=37)$ whose case/control status was unknown to them. Results of these studies were satisfactory, with $100 \%$ agreement for depressive episode, substance use disorder, schizophrenia and organic mental disorder, and $\kappa$ values ranging from 0.89 to 1.0 for different categories of ICD-10 personality disorders.

\section{Socio-demographic data}

The psychological autopsy interview included enquiry into the marital, employment and socio-economic status of suicides and controls. Living status (whether or not living alone) and any episodes of migration before the suicide or the interview were also recorded. The latter excluded temporary change of residence for work purposes.

\section{Personal history}

We also investigated early parental deprivation (defined as loss of care by one or both parents before the age of 15 years and lasting at least until the age of 15) for whatever reasons (e.g. death of parent or parental separation or divorce) and history of previous suicide attempts among suicides and controls.

\section{Concurrent physical morbidity}

Enquiry about physical problems included the existence of serious illness, chronic pain and disablement. Serious illness included terminal/non-terminal malignant and nonmalignant illness. Chronic pain was rated positively if it had been present in marked degree for at least 6 months. Disablement was assessed in the domains of housing, verbal and non-verbal communication, personal care and outdoor social activities.

\section{Family history of psychopathology and suicidal behaviour}

A detailed family tree was first established. Then the investigators enquired about lifetime history of depressive illness, alcohol or drug misuse and suicidal behaviour (attempted and actual suicide) among the first-degree biological relatives of suicides and controls. A psychiatric diagnosis was made by A.T.A.C. on the basis of interview records.

\section{Stressful life events}

Stressful life events preceding suicide were assessed using the 12 categories in the List of Threatening Experiences (LTE; Brugha et al, 1985), plus three other categories relevant to society in Taiwan. The former include serious illness/injury/assault (subject), serious illness/injury/assault (close relative), death of parent/child/spouse (confidant), death of close family friend/other relative, separation due to marital difficulties, breakup of steady relationship, serious problem with close friend/neighbour/ relative, being unemployed or seeking work unsuccessfully for more than 1 month, being sacked from a job, major financial crisis, problems with police or court appearance, and something of value lost or stolen. The latter include failure in important examinations, serious problems between parents (separation, divorce or major rows) and serious events related to children (such as being unemployed, having financial crises, having serious behavioural, legal or marital problems, but excluding major illness or accident, which are in the LTE).

All the events $(n=345)$ gathered in the psychological autopsy interviews were further categorised according to the concept and definition of loss developed in the Life Events and Difficulties Schedule (LEDS; Brown \& Harris, 1989). They were classified into four major types of loss (health, a person, a cherished idea and employment/material possessions) and non-loss events. Loss of a cherished idea may include: (a) the disruption of the subject's expectations of some key person's duty, commitment, faithfulness and trustworthiness; (b) a challenge to subject's belief regarding these qualities in himself (herself), such as self-worth, personal dignity, face, self-identity and competence; (c) a reconfirmation of an existing failure or inadequacy involving self-worth; and (d) loss of a cherished aspiration or frustration of a goal, often concerning security or meaning.

An interrater reliability study concerning the judgement of loss/non-loss for all the events in suicides and controls was carried out by A.T.A.C. and C.-C.C. Since A.T.A.C. was not blind to subjects' case/ control status, independent assessment based on description of events was conducted by C.-C.C. who was blind to subjects' case/control status and is experienced in the use of the LEDS (Chen et al, 1995). The $\kappa$-coefficient between the two assessors was 0.95 .

\section{Data analysis}

Since our suicides and controls were individually matched, conditional logistic regression was applied for data analysis. Univariate regression analysis was first performed to assess the individual effect of psychosocial factors on the risk of suicide. Multivariate regression analysis was then carried out to examine the 
independent and interactive effects of all the significant psychosocial factors and psychiatric disorders. The statistical package EGRET for Windows (CYTEL Software Corporation, 1999) was used for these analyses.

\section{RESULTS}

Tables 1-4 illustrate the distribution of psychosocial factors among suicides and controls. In Table 1, it can be seen that suicides were significantly more likely to be unmarried, unemployed and non-skilled than were controls. They were also significantly more likely to have lived alone before suicide than were controls (before interview). However, the proportions of suicides and controls living alone were not high (less than 10\%). Compared to controls, a significantly higher proportion of suicides had moved house in the past year.

\section{Personal history and concurrent physical morbidity}

Suicides had a significantly higher rate of previous suicide attempts than controls. They had also experienced early parental deprivation more frequently than controls (Table 2).

Suicides were found to have a significantly higher rate of serious physical illness before committing suicide than controls (before interview). They also had significantly higher rates of chronic pain and disablement.

\section{Family history of psychopathology}

Table 3 shows that suicides were significantly more likely than controls to have had first-degree relatives with a history of suicidal behaviour (attempted and actual suicide) or depressive illness, but not with alcohol or drug use disorders. The high prevalence of alcohol or drug use disorders among suicides and controls can be attributed to the high prevalence of alcoholism among Taiwanese aborigines found in our previous epidemiological studies (Cheng $\&$ Chen, 1995).

\section{Recent life events}

A significantly higher proportion of suicides had experienced loss events in the year before suicide than controls (before interview) (Table 4). There was, however, no such trend for non-loss events. The most
Table I Psychosocial factors of suicide: sociodemographic profile (univariate conditional logistic regression analysis)

\begin{tabular}{lccc}
\hline & $\begin{array}{c}\text { Suicides }(n=\mathrm{II} 3) \\
n(\%)\end{array}$ & $\begin{array}{c}\text { Controls }(n=226) \\
n(\%)\end{array}$ & $\begin{array}{c}\text { Odds ratio } \\
(95 \% \mathrm{Cl})\end{array}$ \\
\hline Unmarried & $56(49.6)$ & $77(34.1)$ & $2.4(1.4-4.2)^{* *}$ \\
Unemployed & $73(64.6)$ & $102(45.1)$ & $3.5(1.9-6.5)^{* * *}$ \\
Non-skilled worker' & $81(7 \mathrm{I} .7)$ & $107(47.3)$ & $3.6(2.0-6.3)^{* * *}$ \\
Living alone & $10(8.8)$ & $7(3.1)$ & $4.0(1.2-13.1)^{*}$ \\
Migrated & $29(25.7)$ & $30(13.3)$ & $3.7(I .7-8.2)^{* * *}$ \\
\hline
\end{tabular}

I. Including 'housewives' and the retired.

$* P<0.05 ; * * P<0.01 ; * * * P<0.001$.

Table 2 Psychosocial factors of suicide: personal history and concurrent physical morbidity (univariate conditional logistic regression analysis)

\begin{tabular}{lccc}
\hline & $\begin{array}{c}\text { Suicides }(n=\mathrm{II} 3) \\
n(\%)\end{array}$ & $\begin{array}{c}\text { Controls }(n=226) \\
n(\%)\end{array}$ & $\begin{array}{c}\text { Odds ratio } \\
(95 \% \mathrm{Cl})\end{array}$ \\
\hline $\begin{array}{l}\text { Early parental deprivation } \\
\text { Previous suicide attempt }\end{array}$ & $32(28.3)$ & $37(16.4)$ & $2.1(1.2-3.6)^{* *}$ \\
Poor physical health & $24(21.2)$ & $9(4.0)$ & $5.8(2.6-13.0)^{* * *}$ \\
$\quad \begin{array}{l}\text { Serious illness } \\
\text { Chronic pain }\end{array}$ & $36(31.9)$ & $42(18.6)$ & $2.2(1.3-3.8)^{* *}$ \\
Disablement & $21(18.6)$ & $16(7.1)$ & $3.3(1.6-6.9)^{* *}$ \\
\hline
\end{tabular}

$* * P<0.01 ; * * * P<0.001$

Table 3 Psychosocial factors of suicide: family history of psychopathology and suicidal behaviour (univariate conditional logistic regression analysis)

\begin{tabular}{lccc}
\hline Family history (first-degree) & $\begin{array}{c}\text { Suicides }(n=\mathrm{II}) \\
n(\%)\end{array}$ & $\begin{array}{c}\text { Controls }(n=226) \\
n(\%)\end{array}$ & $\begin{array}{c}\text { Odds ratio } \\
(95 \% \mathrm{Cl})\end{array}$ \\
\hline Suicidal behaviour & $20(17.7)$ & $13(5.8)$ & $4.2(\mathrm{I} .8-9.6)^{* * *}$ \\
Alcohol and drug use disorders & $54(47.8)$ & $1 \mathrm{II}(49.1)$ & $0.9(0.5-1.7)$ \\
Depressive illness & $25(22.1)$ & $25(I I . I)$ & $2.8(\mathrm{I} .4-5.6)^{* *}$ \\
\hline
\end{tabular}

I. Including attempted or actual suicide.

$* * P<0.01 ; * * * P<0.001$

Table 4 Psychosocial risk factors of suicide: life events in the 12 months before suicide or interview (control group) (univariate conditional logistic regression analysis)

\begin{tabular}{lccc}
\hline & $\begin{array}{c}\text { Suicides }(n=\mathrm{II} 3) \\
n(\%)\end{array}$ & $\begin{array}{c}\text { Controls }(n=226) \\
n(\%)\end{array}$ & $\begin{array}{c}\text { Odds ratio } \\
(95 \% \mathrm{Cl})\end{array}$ \\
\hline Loss events' $^{\prime}$ & $95(84.1)$ & $73(32.3)$ & $9.8(5.2-18.7)^{* * *}$ \\
Health & $15(13.3)$ & $13(5.8)$ & $2.4(1.1-5.1)^{*}$ \\
Person & $39(34.5)$ & $22(9.7)$ & $5.1(2.7-9.7)^{* * *}$ \\
Cherished idea & $68(60.2)$ & $42(18.6)$ & $7.5(4.1-13.8)^{* * *}$ \\
Material possession & $22(19.5)$ & $11(4.9)$ & $5.0(2.2-11.3)^{* * *}$ \\
Non-loss events & $28(24.8)$ & $47(20.8)$ & $1.3(0.7-2.2)$ \\
\hline
\end{tabular}

I. Each subject may have more than one type of loss event.

$* P<0.05 ; * * * P<0.001$. 
prevalent loss event among suicides $(60 \%)$ and controls $(18.6 \%)$ was the loss of a cherished idea, followed by the loss of a close relative or confidant (by death or separation).

\section{Psychiatric morbidity}

As previously reported (Cheng, 1995; Cheng et al, 1997), three major mental disorders with high risk for suicide in case-control analysis were an ICD-10 major depressive episode, dependent use of substances (notably alcohol) and emotionally unstable personality disorder (EUPD). The frequencies of these three disorders among suicides were 87.1, 27.6 and $61.9 \%$ respectively.

\section{Interaction between psychosocial and psychiatric factors}

In multivariate logistic regression analysis of all the significant psychosocial factors illustrated in Tables 1-4 and the three psychiatric disorders (major depressive episode, substance dependence and EUPD), five independent effects from major depressive episode, substance dependence, EUPD, loss event and suicidal behaviour in first-degree relatives were derived. There was no significant interaction between any of the independent variables (Table 5). The strongest effect was from depressive episode, followed by loss event.

\section{DISCUSSION}

\section{Methodological considerations}

This paper analyses events that took place during the 12 months preceding suicide or interview (for controls). This section considers the occurrence of major common life events that were found to be moderately to markedly stressful in a high proportion (at least over $50 \%$ ) of subjects in a general population sample in a previous community study of mental disorders in Taiwan (Cheng, 1989).

\section{Recall bias}

The key methodological issues raised by this study have been discussed in detail elsewhere (Cheng, 1995). As this is a psychological autopsy study, a systematic recall bias on the part of informants of suicides is to some extent inevitable. In considering life events, for example, informants may either underreport major personal events of suicides because they were not aware of them, or overreport events because of the informant's personal psychological reaction to the suicide (Heikkinen et al, 1993).

\section{Use of controls}

The inclusion of controls in some psychological autopsy studies attempts to overcome these potential information biases in the assessment of suicide risk. An improvement to this strategy is to interview informants for both suicides and controls.

Table 5 Joint effects of psychosocial and psychiatric risk factors of suicide' (multivariate conditional logistic regression)

\begin{tabular}{|c|c|c|}
\hline & Odds ratio $(95 \% \mathrm{Cl})$ & $P$ \\
\hline \multicolumn{3}{|l|}{ Major depressive episode } \\
\hline Absent & 1.0 & \\
\hline Present & $41.2(10.6-160.4)$ & $<0.001$ \\
\hline \multicolumn{3}{|l|}{ Substance use disorder } \\
\hline Non-dependent use & 1.0 & 0.050 \\
\hline Dependent use & $3.2(1.0-10.4)$ & \\
\hline \multicolumn{3}{|c|}{ Emotionally unstable personality disorder } \\
\hline Absent & 1.0 & \\
\hline Present & $4.3(1.1-16.9)$ & 0.034 \\
\hline \multicolumn{3}{|l|}{ Loss events } \\
\hline Absent & 1.0 & \\
\hline Present & $6.1(2.1-18.2)$ & 0.001 \\
\hline \multicolumn{3}{|c|}{ Suicidal behaviour in first-degree relatives } \\
\hline Absent & 1.0 & \\
\hline Present & $5.2(1.3-21.2)$ & 0.022 \\
\hline
\end{tabular}

Only a few studies (e.g. Gould et al, 1996) apart from the present one have done so. This strategy can largely overcome the bias from underreporting, but that of overreporting is important and difficult to control.

\section{Diagnostic validity}

It has been reported, however, that the diagnoses obtained from psychological autopsy are reliable, valid and unaffected by the bereavement (Brent et al, 1988). One recent study comparing data from psychological autopsy with that from medical records has demonstrated a satisfactory consistency between them (Kelly \& Mann, 1996).

\section{Psychosocial risk factors for suicide}

This study has comprehensively examined the effects of major psychosocial risk factors for suicide found in previous work among adult suicides in a non-Western society. In univariate regression analysis, nearly all of these factors were found to have a significant association with the risk of suicide. The only exception is the lack of a significant contribution to suicide risk from a family history of alcohol and drug use disorders, and this might be due to the very high prevalence of alcoholism among the two aboriginal groups (Cheng \& Chen, 1995).

\section{Recent life events}

Most of the previous studies investigating the relationships between recent life events and suicide have focused on psychiatric patients (both suicides and living controls) and have had small sample size (Heikkinen et al, 1994), which makes it difficult to examine the power of an association. Only a few studies involve representative suicides and normal controls from the general population (e.g. Bunch, 1972; Foster et al, 1999). These more representative studies have generally found that recent life events play an important role in precipitating suicide. Most of the significant events found in these studies were covered by the 12 categories of the LTE, and were similarly identified in this study.

This study is the first to use the concepts of loss and non-loss events (as developed in the LEDS) in the study of suicide. It was found that only loss events have a significant contribution to the risk of suicide. It is interesting to find that the loss of a cherished idea (which frequently coexisted 
with the loss of a person, health and material possession) exerted the strongest effect. It might be argued that loss of a cherished idea probably acts as the core component of loss events, a notion with implications for psychosocial intervention among people with depression who encounter loss.

\section{Family history of suicidal behaviour}

The effect of a family history of suicidal behaviour was independent of demographic, psychosocial and psychiatric factors. It was also independent of familial environmental factors, including early parental deprivation and family history of psychopathology (depressive disorders and substance use disorders). Similar results were reported from recent case-control studies among adolescent suicides in the USA, in which the familial aggregation of attempted and actual suicides was found to have persisted after controlling for family psychopathology in first-degree relatives (Brent et al, 1996; Gould et al, 1996) and poor parent-child relationships (Gould et al, 1996). More research is needed to clarify possible genetic and environmental contributions.

\section{Interaction between psychosocial and psychiatric factors}

Although most of the psychosocial factors exerted significant individual effects on the risk of suicide, only loss events and a family history of suicidal behaviour retained their independent effects after having been adjusted for the effects of depressive episode, substance dependence and EUPD in multivariate regression. Our finding indicates that major depressive episode is the most important risk factor for suicide.

The finding that most of the psychosocial factors were confounded by the five significant factors may imply that the former may largely act as a concomitant factor or the consequence of the latter. To give an example, a man with personality disorder may end up divorced and/or living alone and have experienced a loss of the expectation that his family members will stay with him to look after him (especially suffer from a severe depressive episode leading to suicide. Familial/genetic factors could act upon any of these factors.

The independent effects of mental disorder and loss events found in this study in a non-Western culture). He may then

\section{CLINICAL IMPLICATIONS}

- Significant risk factors for suicide include loss events, suicidal behaviour in firstdegree relatives, ICD-10 major depressive episodes, emotionally unstable personality disorder and substance dependence.

- The most important type of loss event for the risk of suicide is the loss of a cherished idea. Non-loss events do not increase the risk.

Intervention and management for loss events and major depressive episodes among emotionally unstable subjects with a family tendency of suicidal behaviour, frequently also comorbid with alcohol or other substance dependence, may prove to be most effective for suicide prevention in different populations.

\section{LIMITATIONS}

- There is some degree of systemic bias from interview and retrospective memory effect with informants in suicides and controls.

- The use of living controls makes it difficult to control possible psychological reactions to suicide among the informants (relatives).

- The temporal relationship between loss event and mental disorders leading to suicide has not been investigated.

ANDREW T. A. CHENG, FRCPsych, Division of Epidemiology, Institute of Biomedical Sciences, Academia Sinica, Taipei, Taiwan; TONY H. H. CHEN, PhD, Institute of Epidemiology, College of Public Health, National Taiwan University, Taipei, Taiwan; CHWEN-CHEN CHEN, MRCPsych, Department of Psychiatry, National Cheng Kung University, Tainan, Taiwan; RACHEL JENKINS, FRCPsych, Director of WHO Collaborating Centre, Institute of Psychiatry, King's College London, UK

Correspondence: Professor Andrew T. A.Cheng, Division of Epidemiology, Institute of Biomedical Sciences, Academia Sinica, Taipei, Taiwan. Fax: +8862 2785 3569; e-mail:

bmandrew@ccvax.sinica.edu.tw

(First received 3 December 1999, final revision 17 April 2000, accepted 17 April 2000) may imply that loss events have a strong effect in precipitating mental disorder (notably depressive episode) leading to suicide. However, loss events may frequently appear as the consequence of mental disorders, or may indeed come together with suicide from mental disorders. One of the optimal strategies to clarify this complex process would be to investigate the pathways to suicide, a research area that has not been well studied.

\section{Implications for suicide prevention}

The findings in this study have implied that suicide is most likely to result from the effects of mental disorders (notably a depressive episode, substance dependence and EUPD) and major loss events on predisposed individuals in both Eastern and Western societies. Thus, effective intervention and management of loss events and major depressive episodes among emotionally unstable subjects (particularly those with a family history of suicidal behaviour and frequently also comorbid with alcohol or other substance dependence), may prove to be most effective for suicide prevention in different populations.

\section{ACKNOWLEDGEMENTS}

The authors acknowledge the assistance of several coroners and prosecutors in Taiwan, and the excellent performance of their assistants J. Y. Kao and H.M. Lin. 


\section{REFERENCES}

American Psychiatric Association (1987) Diagnostic and Statistical Manual of Mental Disorders (3rd edn, revised) (DSM-III-R). Washington, DC: APA.

Barraclough, B., Bunch, J., Nelson, B., et al (1974) A hundred cases of suicide: clinical aspects. British Journal of Psychiatry, 125, 355-373.

Brent, D. A., Perper, J. A., Kolko, D. J., et al (1988)

The psychological autopsy: methodological

considerations for the study of adolescent suicide. Journal

of the American Academy of Child and Adolescent

Psychiatry, 27, 362-366.

_ , Bridge, J., Johnson, B. A., et al (1996) Suicida behavior runs in families: a controlled family study of adolescent suicide victims. Archives of General Psychiatry, 53, $1145-1152$

Brown, G. \& Harris, T. (1989) Life Events and

Psychiatric Illness. London: Unwin Hyman.

Brugha, T. S., Bebbington, P., Tennant, C., et al (1985) The List of Threatening Experiences: a subset of 12 life event categories with considerable long-term contextual threat questionnaire. Psychological Medicine, 15, 189-194.

Bunch, J. (1972) Recent bereavement in relation to suicide. Journal of Psychosomatic Research, 16, 361-366.

Chen, C. C., David, A. S., Nunnerley, H., et al (1995) Adverse life events and breast cancer: case-control study. British Medical Journal, 3II, I527-I530.
Cheng, A. T. A. (1995) Mental illness and suicide: a case-control study in East Taiwan. Archives of General Psychiatry, 52, 594-603.

_, Mann, A. H. \& Chan, K. A. (1997) Personality disorder and suicide. A case-control study. British Journal of Psychiatry, 170, 44I-446.

Cheng, T. A. (1989) Psychosocial stress and minor psychiatric morbidity: a community study in Taiwan. Journal of Affective Disorders, 17, 137-152.

_ \& Chen, W. J. (1995) Alcoholism among four aboriginal groups in Taiwan: high prevalences and their implications. Alcoholism: Clinical and Experimental Research, 19, 81-91.

CYTEL Software Corporation (1999) EGRET for Windows. Cambridge, MA: CYTEL Software Corporation.

Foster, T., Gillespie, K., McClelland, R., et al (1999) Risk factors for suicide independent of DSM-III-R Axis I disorder. British Journal of Psychiatry, 175, 175-179.

Gould, M. S., Fisher, P., Parides, M., et al (1996) Psychosocial risk factors of child and adolescent completed suicides. Archives of General Psychiatry, 53 II55-1162.

Heikkinen, A., Aro, H. \& Lonnqvist, J. (1993) Life events and social support in suicide. Suicide and LifeThreatening Behaviour, 23, 343-358.

_, _ \& _ (1994) Recent life events, social support and suicide. Acta Psychiatrica Scandinavica Supplementum, 377, 65-72.
Kelly, T. M. \& Mann, J. J. (1996) Validity of DSM-III-R diagnosis by psychological autopsy: a comparison with clinician ante-mortem diagnosis. Acta Psychiatrica Scandinavica, 94, 337-343.

Lesage, A. D., Boyer, R., Gruenberg, F., et al (1994) Suicide and mental disorders: a case-control study of young men. American Journal of Psychiatry, I5I, 1063-1068.

Mann, A. H., Jenkins, R., Cutting, J. C., et al (1981) The development and use of a standardized assessment of abnormal personality. Psychological Medicine, II, 839-847.

Robins, E., Murphy, G. E., Wilkinson, R. H., et al (1959) Some clinical considerations in the prevention of suicide based on a study of 134 successful suicides. American Journal of Public Health 49 888-898.

Sainsbury, P. (1986) The epidemiology of suicide. In Suicide (ed. A. Roy), pp. 17-40. Baltimore, MA: Williams \& Wilkins.

Shaffer, D., Gould, M. S., Fisher, P., et al (1996) Psychiatric diagnosis in child and adolescent suicide. Archives of General Psychiatry, 53, 339-348.

World Health Organization (1992) The Tenth Revision of the International Classification of Diseases and Related Disorders (ICD-I0). Geneva: $\mathrm{WHO}$ 